\title{
Bio-Degradation Study of ABS Protein Filled Nano Composite
}

\author{
M. Khaj ${ }^{1}$, N. Goudarzian ${ }^{1} *$, Kh. Yousefi ${ }^{2}$ \\ ${ }^{1}$ Department of Applied Chemistry, Faculty of Sciences, Shiraz Branch, Islamic Azad University, Shiraz, Iran \\ ${ }^{2}$ Department of Materials Science and Engineering, School of Engineering, Shiraz University, Shiraz, Iran
}

Received: 06/09/2020

Accepted: 08/11/2020

Published: 20/03/2021

\begin{abstract}
In this work we report the particular preparing as well as properties of nano blend according to acrylonitrile/butadiene/styrene terpolymer using improved nano silica, and also casein, in particular, most of us studied the effects of filler injections concentration on morphology, as well as hardware overall performance, paying attention our consideration on the consequence with the biodegrad ation phenomena with the casein modifiers. ABS/nano Si and casein blends are assumed to be biodegradable since both components are biodegradable in a variety of microbial circumstances. The particular processing and mechanical properties involving casein and also ABS/nano Si blends have been well investigated and submitted to degradation by dirt interment tests in perforated boxes for 6 months and later analyzed. After destruction, blends along with casein displayed FTIR signals of minimal intensity in comparison to the original blends. These results exposed that ABS/nano Si's biodegradability may be improved until casein is added to it. as to the actual mechanical properties, the effect of casein content on the strain at break of the nano composites, it is seen that the strain at break and impact strength of the nano composites get worse with the addition of casein where it decreases with increasing casein content while Young's modulus is higher than that of pure ABS.
\end{abstract}

Keywords: Nano composites; Acrylonitrile/butadiene/styrene terpolymer; Bio-degradation; Nano Silica

\section{Introduction}

The particular plastic-type industry offers knowledgeable some sort of exceptional progress over the last several years, and also parts have become found in every part connected with enterprise and also lifestyle. The actual important enhance inside pockets generation and also product or service era has brought in the also important enhance inside plastic material convenience. Plastic-type material waste materials, whoever the main source will be product packaging, is among the members towards waste materials administration difficulty acrylonitrile/butadiene/styrene terpolymer (ABS) plastic material is probably the many dominating packaging in addition to industrial supplies in today's modern society and it is unable regarding self-decomposition (1-4).

Poly (Acrylonitrile/butadiene/styrene) (ABS) is usually semi crystalline thermoplastic polyester widely used in textile fibers making, food packaging as well as liquefied containers, thermoforming purposes as well as engineering resins frequently in combination with fillers during the past years (59). There has been growing attention to some courses connected with the biodegradation plastic composites in which acquiescence to help the environment, and also nanocomposites, based on the dispersion of fillers at a nanometric scale. Among the various kinds of nanoparticles, lamellar fillosilicates just like montmorillonite and have been carefully investigated (10-13). Polymer blending is a useful method to beget materials with specific enhanced properties. The blending of polyolefins with engineering plastics is a path to improve the mechanical confidants of polymeric materials another widespread route is the basis on the development of nanocomposites (14-16). The original aims of nanoparticles addition to being able to immiscible polymer blends are generally how the morphology of the blends is usually affected by nanoparticles and also whether these types of additives can easily play the role of compatibilizer in the blends (17-19). It must be noted that the mechanism of action of nanoparticles to modify the actual morphology are investigated, we aimed to detect nano silica localization within an immiscible $\mathrm{ABS} /$ nanoSi blend nanocomposites applying the actual rheological. In this function, an endeavor was also meant to set up a correlation concerning localization involving nanosilica and it is an effect on morphology. The results revealed these rheological methods, especially the oscillation mode, were trustworthy tools to find clay-based localization specifically on high silica loading. From the morphological research, it had been identified which the localization associated with nano silica within the matrix phase of the mixes led to improved development in the morphology (20-24). Caseins are animal proteins and are commonly found in milk, making up $80 \%$ of the proteins in cow milk and between 60 and $65 \%$ of the proteins in human milk. Casein molecular weight is between 1,000 and 20,000 g.mol ${ }^{-1}$. Caseins include four different types. Casein is the predominant protein and is characterized by an open, random coil structure. By treating acid-precipitated caseins with alkali solution, caseinates are produced. Both caseins and caseinates from transparent films from aqueous solutions without any treatment based on hydrogen bonds. Caseins have shown to be useful in a great number of fields

\footnotetext{
*Corresponding author: N. Goudarzian, Department of Applied Chemistry, Faculty of Sciences, Shiraz Branch, Islamic Azad
} University, Shiraz, Iran. E-mail: ngoudarzian@iaushiraz.ac.ir 
such as adhesives, controlled releases, and biomedical applications (25-28).

\section{Experimental details \\ 2. 1 Materials}

Styrene acrylonitrile (SAN), (SAN w1540) was supplied by Iran Petro Chemical Co., Ltd. (Iran), [MFR $=50 \mathrm{~g} / 10 \mathrm{~min}$ $\left(200{ }^{\circ} \mathrm{C} / 21.6 \mathrm{Kg}\right)$, Density $\left.=1.04 \mathrm{~g} / \mathrm{cm}^{3}\right]$ and Styrene/Butadiene/Styrene (SBS) was supplied by Amole Plastic, Co, Ltd. Iran. Casein is a commercial material; it was brought from local suppliers and used as received, nano silica used in this study is commercially available as fine amorphous, nonporous, and typically spherical particles, white color, specific gravity 1.12 , particle size $8-20 \mathrm{~nm}, \mathrm{SiO}_{2}$ content $99.1 \%$ and glycerol $(\mathrm{Gl}) 99.5 \%$ was a commercial grade without any treatment. For the preparation of ABS nano composite from SAN and SBS and nano silica we used SAN and SBS granules that were mixed and deride at temperature $80-90{ }^{\circ} \mathrm{C}$ for $6 \mathrm{~h}$ and ABS were prepared using a laboratory scale twine extruder (DSE) $(\mathrm{L} / \mathrm{D}=40, \mathrm{D}=20 \mathrm{~mm})$ which could be operated at different amount SAN/ SBS (5, 10, 20, 30, $40 \mathrm{w} \%)$ and amount of nano silica $1,3,5 \mathrm{w} \%$ at $160-190^{\circ} \mathrm{C}$ which could be operated at a constant speed (200rpm). The physical and mechanical study of these blends showed that the ABS with $20 \mathrm{w} \%$ SBS and $3 \mathrm{w} \%$ have the optimized characteristics so we used this blends for biodegradation studies.

Composites preparation ABS granules and casein powder were mixed manually and dried at temperature $110 / 125^{\circ} \mathrm{C}$ for a $6 \mathrm{~h}$. To improve the mixing of the blend components, the casein was subjected to plasticization with glycerol. Glycerol was chosen as a softener because of its high plasticizing ability relative to that of casein and a quite satisfactory one relative to ABS, as well as because of its nontoxicity and rather high thermal stability. ABS/casein composites were prepared using a laboratory scale Double screw extruder (DSE) $(\mathrm{L} / \mathrm{D}=28, \mathrm{D}$ $=20 \mathrm{~mm}$ ), which could be operated at different speeds, varied from 0 to100 rpm. The screw has a fluted type mixing section located before the metering zone (29) in this type of mixer the material is forced to pass at high shear stress. This brings in some level of dispersing action besides reorienting the interfacial area and increasing the imposed total strain. The flight depth of the screw in the metering zone was $1.56 \mathrm{~mm}$, and the helix angle $17.7^{\circ}$. The temperatures profile along the barrel of the extruder were set at $160,160,160,190{ }^{\circ} \mathrm{C}$ (from feed zone to die), and the screw speed was 40 RPM. The composites were then extruded through a multi holes die ( 3 $\mathrm{mm}$ ) and the extrudes were left to cool in the air and then fed into a granulator which converted them into granules. The obtained granules were then dried at temperature $110 / 125^{\circ} \mathrm{C}$ for $6 \mathrm{~h}$ before use. The prepared composites and ABS were compressed and the molding temperature for the composites and $\mathrm{ABS}$ were $200,160{ }^{\circ} \mathrm{C}$ respectively. The molded specimens were then cooled to $80^{\circ} \mathrm{C}$ before removal from the mold and cut into a dog bone - shaped sample (ASTM D638) under the air pressure for mechanical testing. The compositions of nanocomposites were $10,15,20 \mathrm{w} \%$ casein. For the mechanical tests of all nano composites with $3 \mathrm{w} \%$ of nano, $\mathrm{Si}$ was collected. The optimum formula for biodegradable exams was obtained ABS $90 \mathrm{w} \%$ and casein $10 \mathrm{w} \%$, ABS $85 \mathrm{w} \%$, and casein $15 \mathrm{w} \%$ and finally, ABS $80 \mathrm{w} \%$ and casein $20 \mathrm{w} \%$ all of them have $3 \mathrm{w} \%$ nano silica.

\subsection{The scanning electron microscope (SEM)}

Utilize a focused beam of high-energy electrons to come up with a variety of signals in the surface area of stable individuals. The actual impulses that obtain via electron sample interactions reveal information about the sample including external morphology chemical composition, as well as crystalline structure and orientation of materials making up the sample. In most applications, data are usually collected over a chosen area of the surface of the sample, as well as a 2dimensional picture is earned which demonstrates spatial variations inside these properties. Places ranging from approximately $1 \mathrm{~cm}$ to 5 microns wide could be imaged in a scanning mode using conventional SEM techniques. The actual SEM is also capable of executing examines of determining place spots for the sample, this method is especially helpful within qualitative. The degree of biodegradation $\mathrm{ABS} / \mathrm{Casein} /$ nano Si blends ended up being measured using their weight fractions and the exploitation with the ABS/Casein/nano Si blends through separation this casein right after 6month.

\section{Results and discussion 3.1 Biodegradation}

3.1.1 Degradation soil burial test The soil burial tests started in October 2014 and continued for 6 months at $35 \pm 2{ }^{\circ} \mathrm{C}$ in an environment in which the relative humidity was not less than $85 \%$. ABS/Casein/nano Si blends were buried in a perforated box to allow the samples to be attacked by the microorganisms and moisture. The box was buried at a depth of $7 \pm 9$ in. beneath the soil surface. After removal, all the samples were carefully washed to stop the degradation and the plastic sheets (thickness $=0.423 \mathrm{~mm}$ ) were stored in darkness until testing. The soil burial tests started in October 2014 and continued for 6 months at $35 \pm 2 \mathrm{oC}$ in an environment in which the selfrelative moisture was not less than $85 \%$. ABS/Casein/nano $\mathrm{Si}$ blends were buried in a perforated box to allow the samples to be attacked by the microorganisms and moisture. The box was buried at a depth of $7 \pm 9$ in. below the soil surface. After removal, all the samples were attentively washed to stop the degradation and the plastic sheets (thickness $=0.423 \mathrm{~mm}$ ) were stored in darkness until testing.

\subsubsection{Weight lost}

After 6 months the films and specimens calculated taking their weight fractions and the weight lost number present in table 1 and Fig. 1

Table 1: Durations of weight loss of ABS with different amounts of casein

\begin{tabular}{|l|l|l|l|}
\hline & SAMPLE (w 10\% casein) & SAMPLE (w 15\% casein) & SAMPLE (w 20\% casein) \\
\hline First weight & $0.671 \mathrm{gr}$ & $0.673 \mathrm{gr}$ & $0.675 \mathrm{gr}$ \\
\hline Weight after 2 months & $0.657 \mathrm{gr}$ & $0.621 \mathrm{gr}$ & $0.590 \mathrm{gr}$ \\
\hline Weight after 4 months & $0.638 \mathrm{gr}$ & $0.605 \mathrm{gr}$ & $0.567 \mathrm{gr}$ \\
\hline Weight after 6 months & $0.618 \mathrm{gr}$ & $0.578 \mathrm{gr}$ & $0.546 \mathrm{gr}$ \\
\hline
\end{tabular}




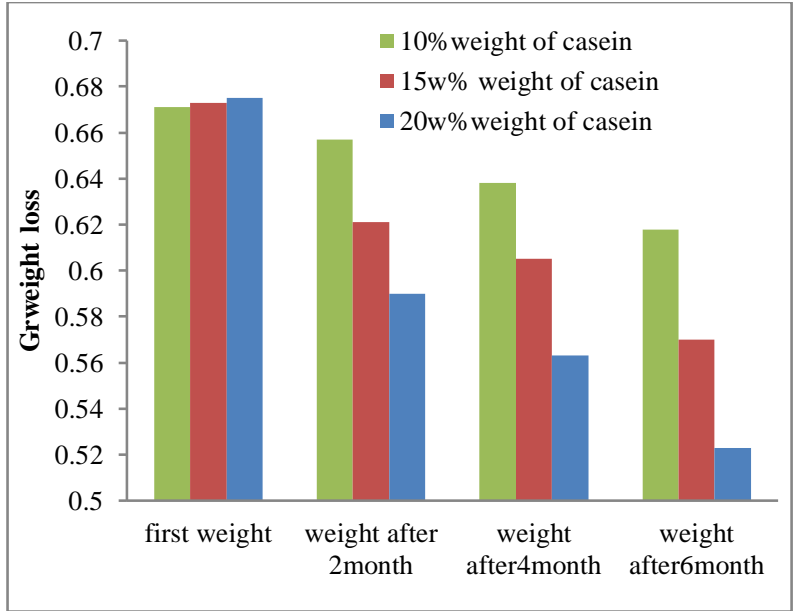

Figure 1: Diagram of weight loss of ABS with different amounts of casein

After the 6 months of soil burial test, the growth of microorganisms on the plastic caused changes in some of its physical and chemical properties that can be detected in the weight lost analysis. From the weight lost curves for $\mathrm{ABS} /$ Casein/nano, Si blends with glycerol, before and after buried for 6 months Fig. 1, it was verified that all the samples presented fewer stages of biodegradation after the period of soil buried test. It was observed that after the soil burial test, biodegradation is about the original samples. However, as the amount of casein is increased the degradability characteristics will increase. This data table 1 indicates that the part of the sample was not degraded during the soil burial test after 6 months.

\subsection{Mechanical properties}

Fig. 2( $a$ and b) shows the effect of casein content on the strain at break of the nanocomposites; it is seen in these figures, that the strain at break of the composites get worse with the increase of casein where it decreases along with increasing casein content, and also the presence of $15 \%$ of casein in the composite caused a steep decline in the strain at break.

Fig. 3(a and b) shows the effect of protein content on Young's modulus for the composites, it could be noted from Fig. 3, that Young's modulus of the composites is higher than that of pure ABS. It could be said that the addition of protein to ABS follows the general trend for filler effects on polymer properties [36]. The modulus increases due to the stiffening effect of protein and the strain at break decrease sharply as the protein content is increased. The increasing casein content higher than $15 \%$ caused a sharp decrease in the stress at break. Figure 4 ( $a$ and $b$ ) shows the effect of casein content on the strain at break of the composites, it is seen in these figures, that the strain at break of the composites get worse with the addition of casein where it decreases with increasing casein content, and the presence of $15 \%$ of casein in the composite caused a steep decline in the strain at break.

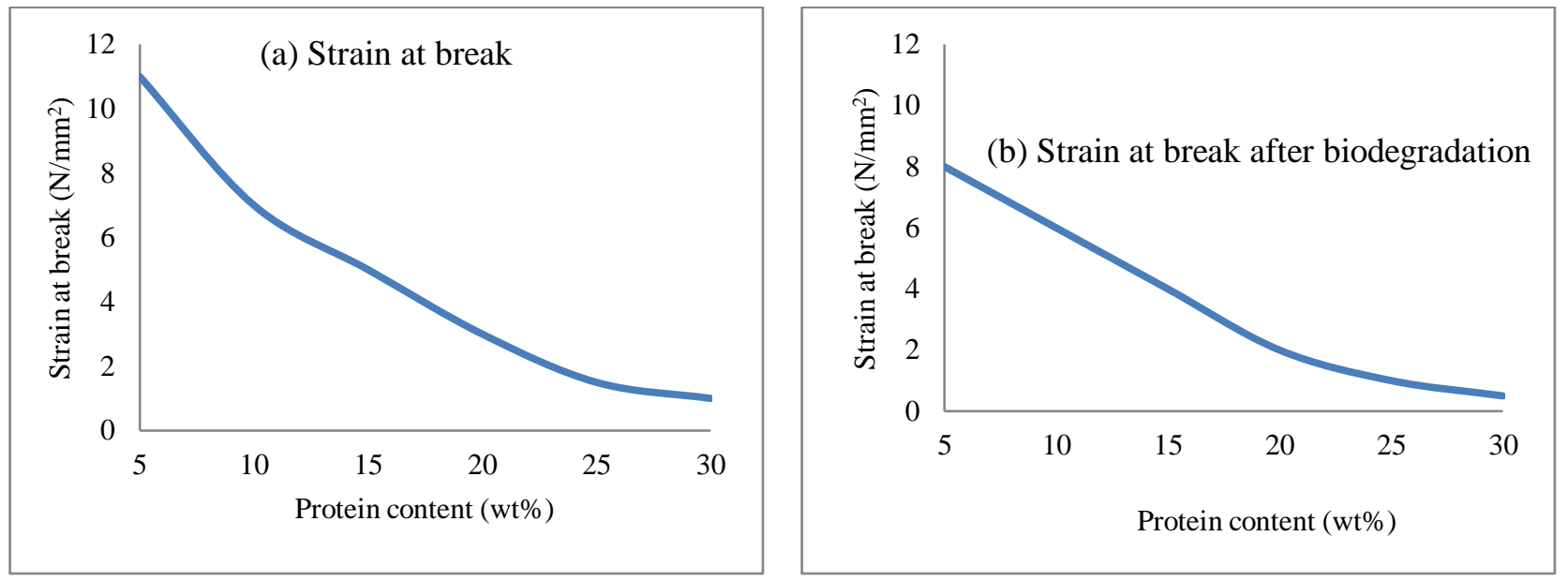

Figure 2: Strain at break versus casein content $(0-30 \mathrm{w} \%)$; (a) before degradation (b) after degradation
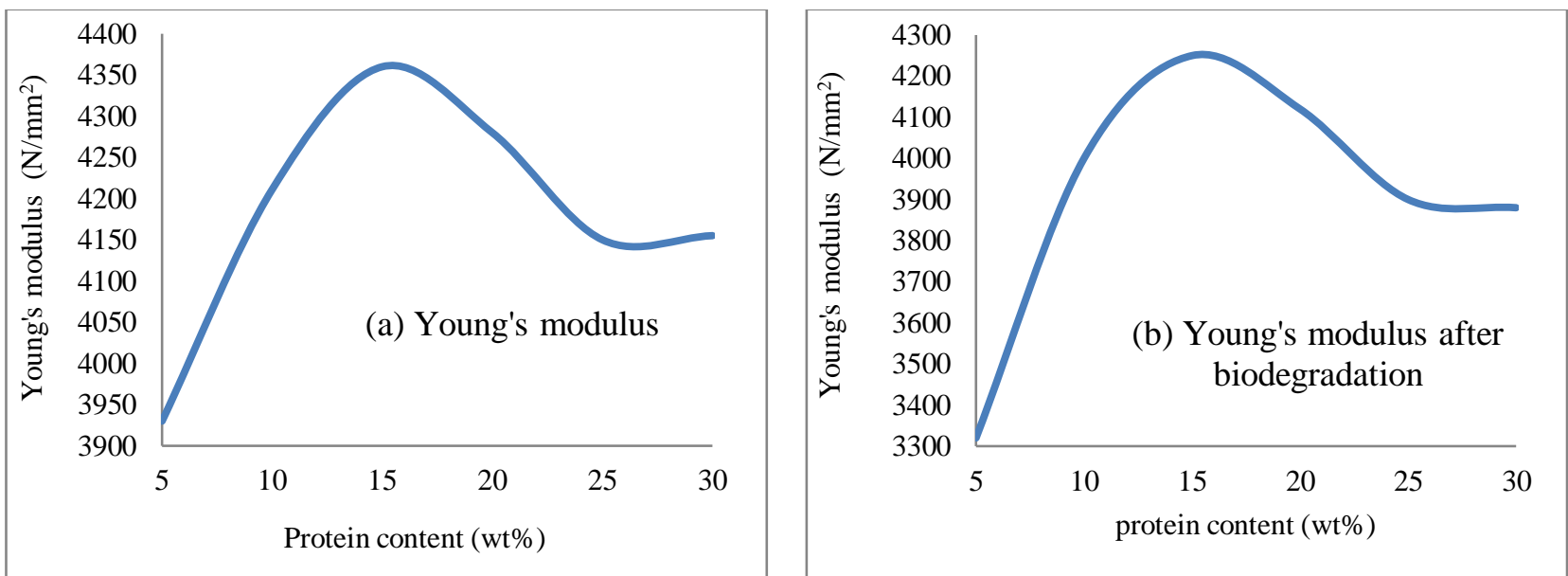

Fig. 3 (a and b) Young's modulus versus casein content (wt. \%); (a) before degradation (b) after degradation 

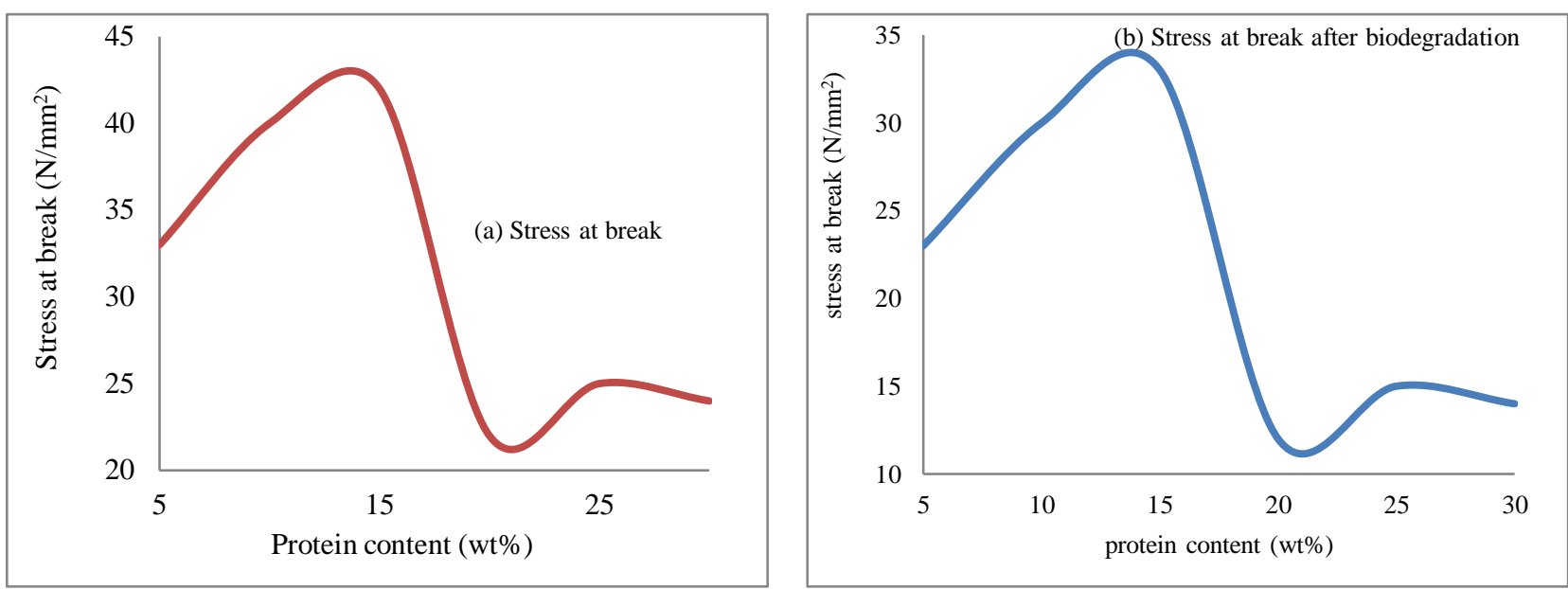

Fig. 4 ( $a$ and b) stress at break versus casein content (wt. \%); (a) before degradation (b) after degradation

Impact tests were performed according to ASTM D-1709 Fig. 5 shows impact strength. The decrease reflects the impact strength with increasing protein content in ABS/Casein/nano Si nanocomposites. It is more and more intense after increasing protein.

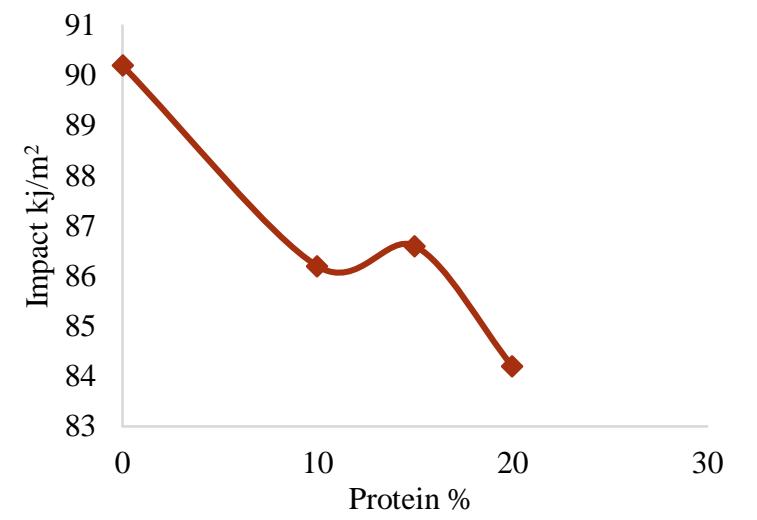

Fig. 5: Impact strength (IS) of the nanocomposites versus casein content $(\mathrm{wt} \%)\left(\mathrm{kj} / \mathrm{m}^{2}\right)$ impact

\subsection{SEM Analysis}

A typical morphology of the destruction of the ABS/Casein/nano Si blends by the break up the casein after 2 and 6 months is shown in Fig. 6 to 9 in these figures the percent of protein was different from $10 \%$ until $20 \%$. The scanning electron micrographs of the ABS/Casein/nano Si blends sheets reveal the destroyed areas of casein that are the starting point of degradation. In SEM micrographs, there are some significant signs in terms of damaged holes and creak between the samples before and after degradation. The diffusion or partition of protein on the plastic surface areas is available for bacterial attack. The number of pores on the surfaces is thus increased. The primary mechanism must be microbial production of casein in or near a pore, followed by diffusion of the microorganisms into pores and diffusion of soluble digestion products back to the surface where degradation would occur.
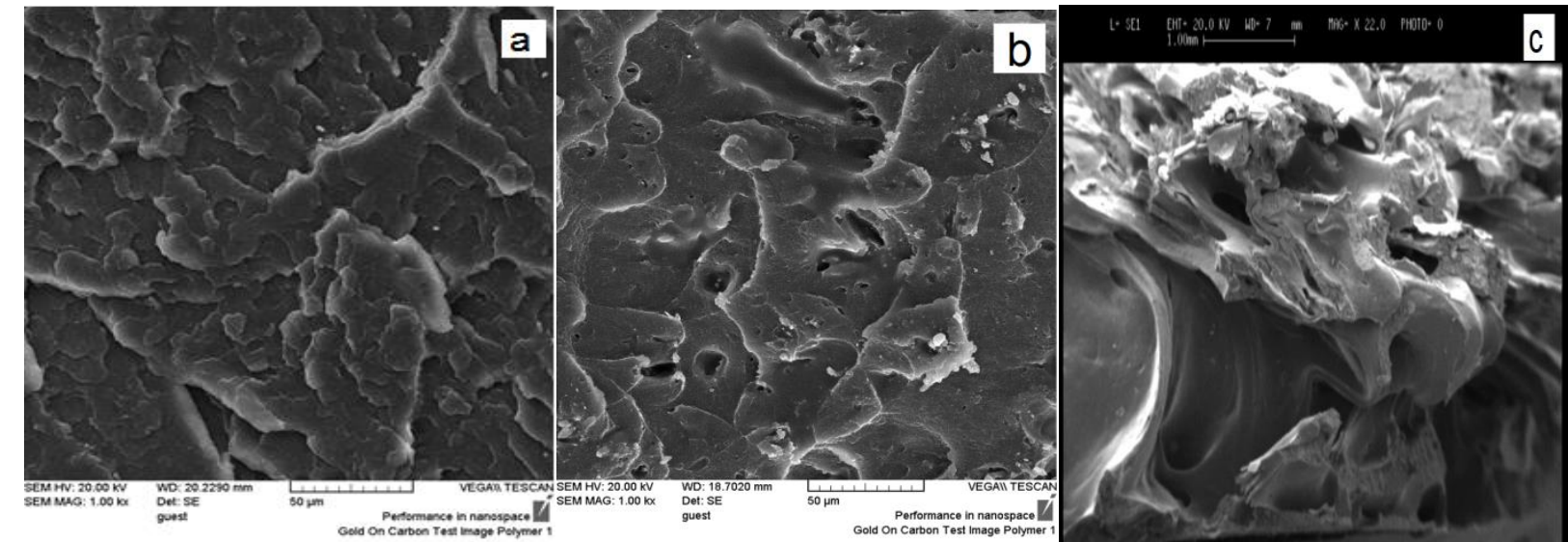

Fig. 6: SEM image of ABS/protein /nano Si nanocomposite before degradation: (a) $10 \mathrm{w} \%$ protein (b) $15 \mathrm{w} \%$ protein (c) $20 \mathrm{w} \%$ protein 


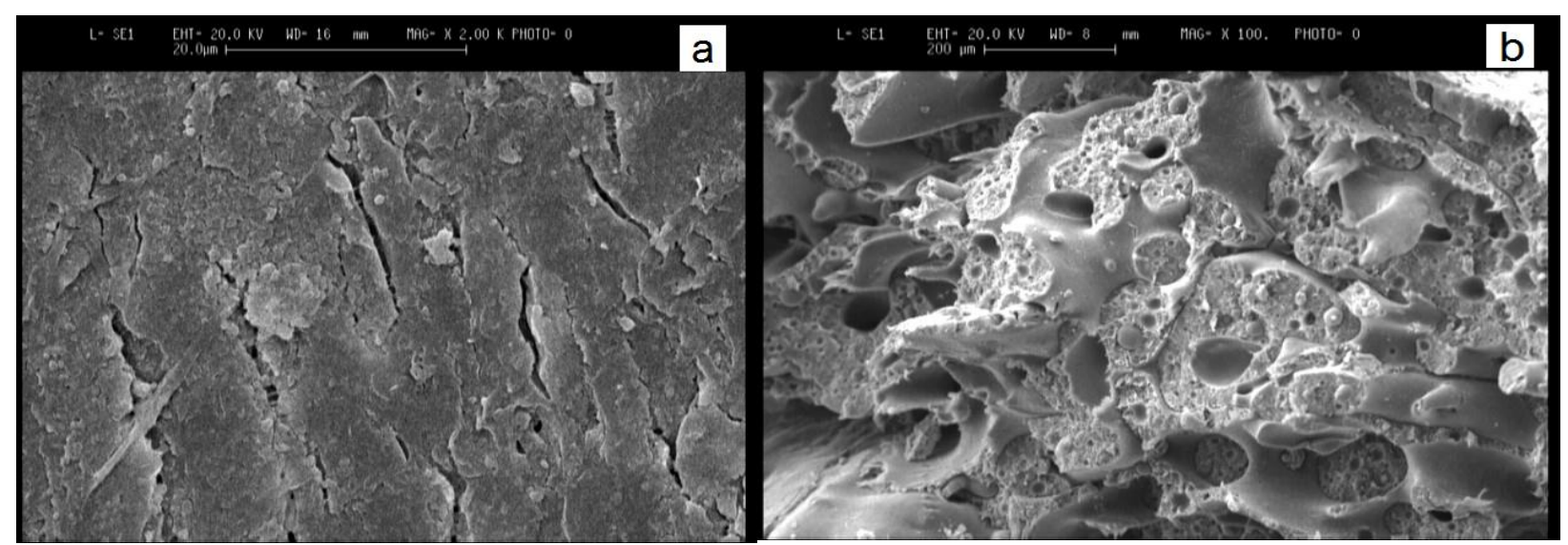

Fig. 7: SEM image of ABS /nano Si nanocomposite with $10 \mathrm{w} \%$ proteins after (a) 2 month (b) 6 month

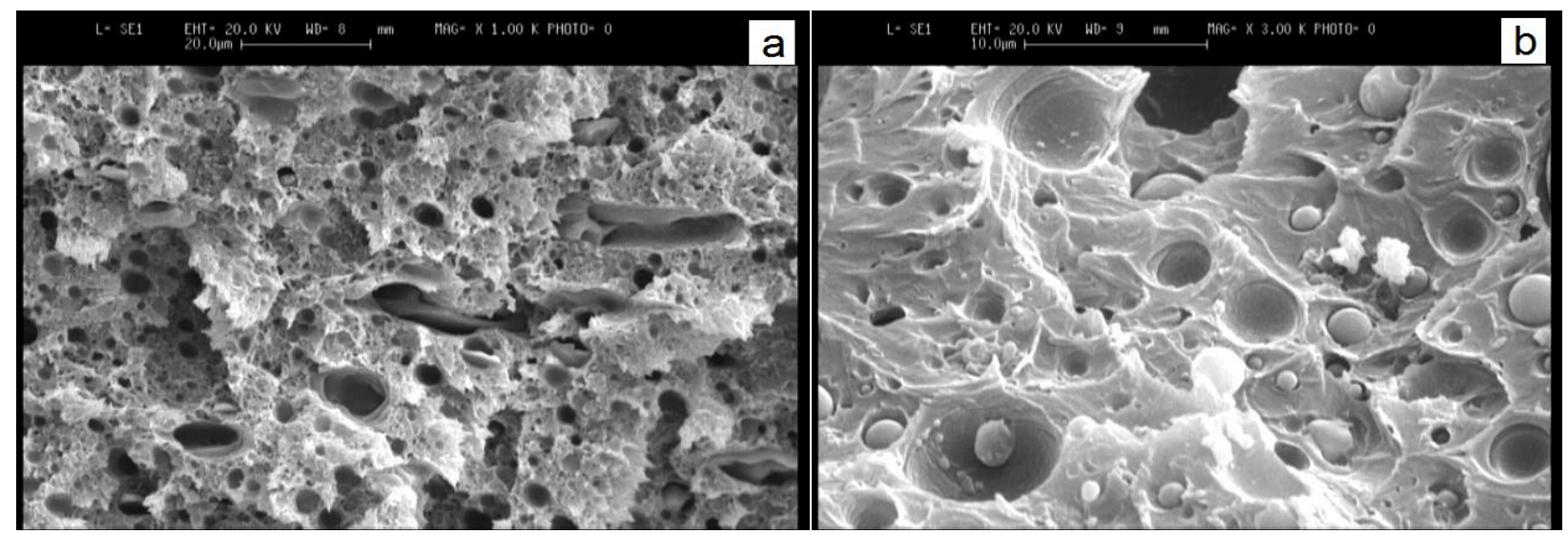

Fig. 8: SEM images of ABS /nano Si nanocomposite with $15 \mathrm{w} \%$ proteins after 2 month (b) 6 month

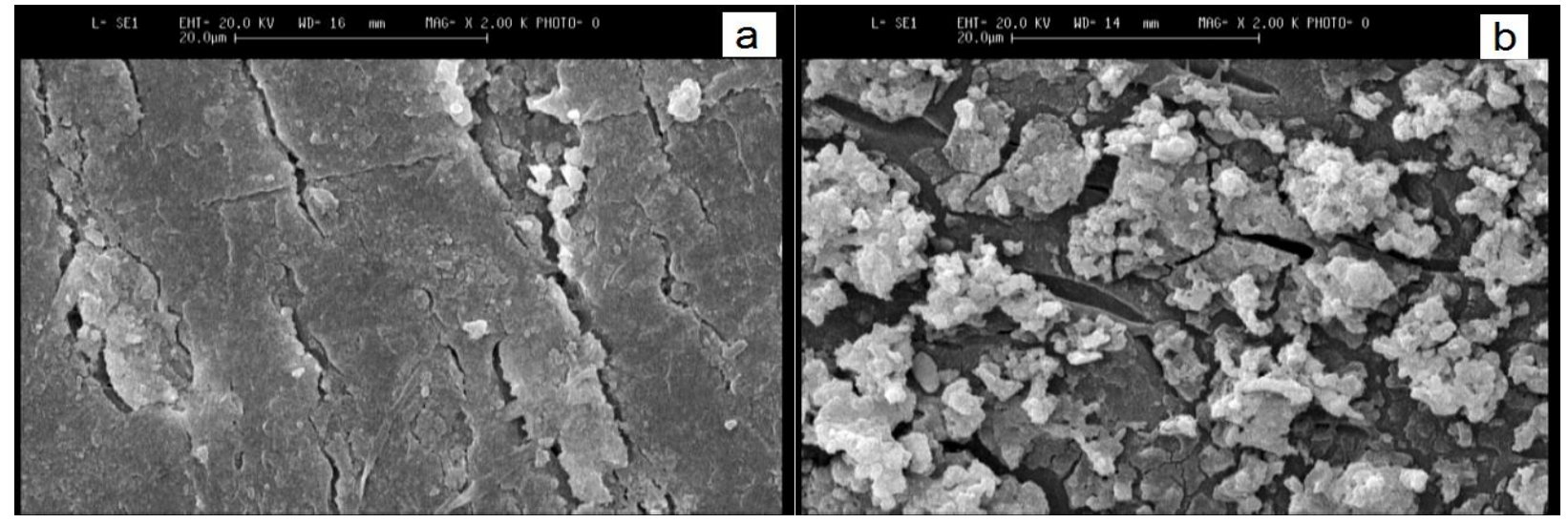

Fig. 9: SEM images of ABS /nano Si nanocomposite with $20 \mathrm{w} \%$ proteins after 2 month (b) 6 month

\subsection{FTIR analysis}

The attendance of casein at contents of $15 \%$ or greater improved the destruction of the blends after 6 months, ABS/nano Si blends together with casein offered merely biodegradation phase with a substantial improve by mass loss. Moreover, all attraction relevant to casein disappeared in FTIR spectra after soil buried test, likely due to the usage of casein by microorganisms. These results revealed that ABS's degradability can be improved when incising casein in the blend and the bacteria's helping promote the biodegradation of ABS nano composite with a considerable increase in mass loss. Break up the casein after 6 months is a lack of protein functional group as carbonyl in $1745 \mathrm{Cm}^{-1}$ wide peak Fig. 10 to 13 . 


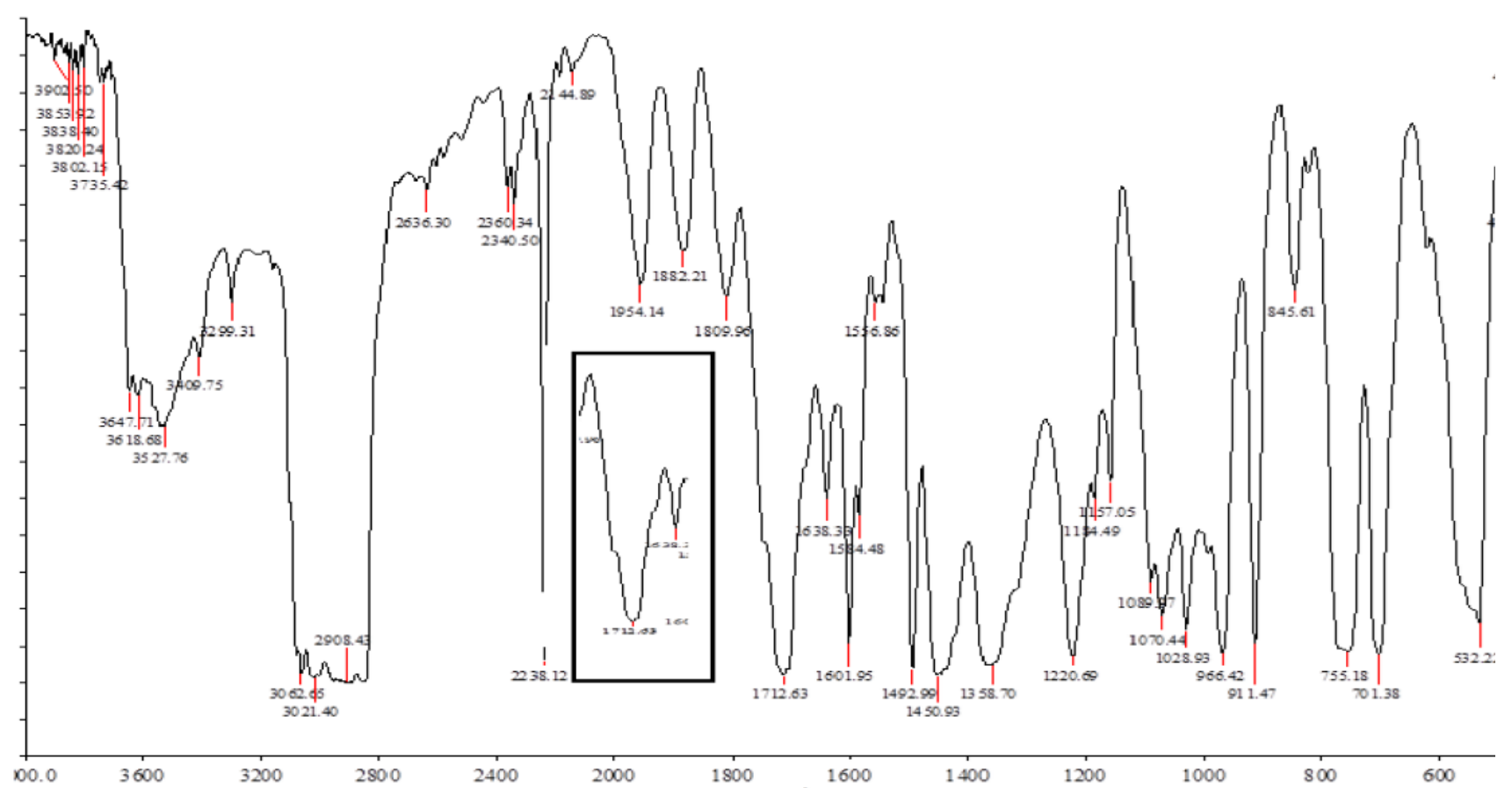

Fig. 10: FTIR of ABS/Casein/nano Si blends before degradation (15\% casein)

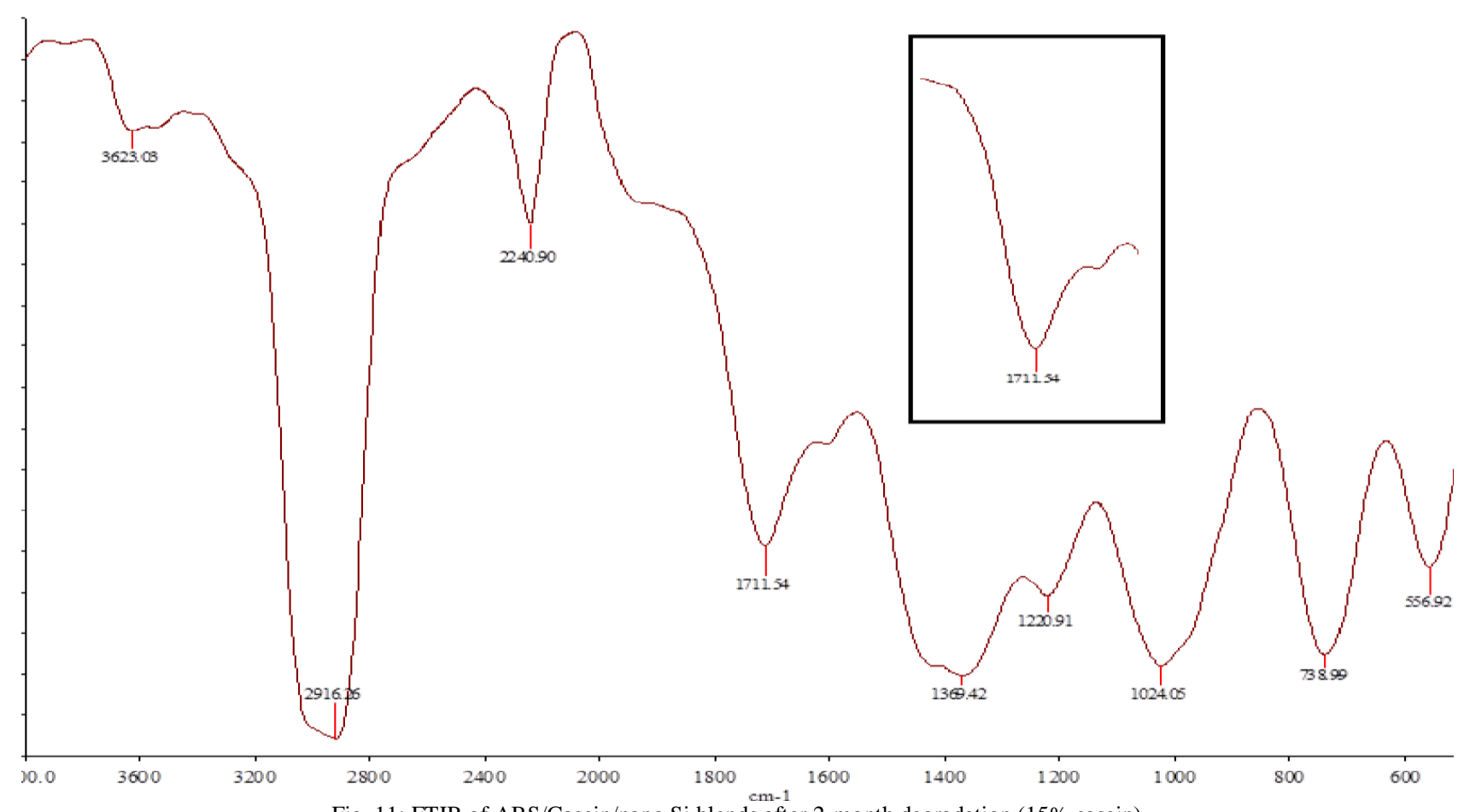

Fig. 11: FTIR of ABS/Casein/nano Si blends after 2-month degradation (15\% casein) 


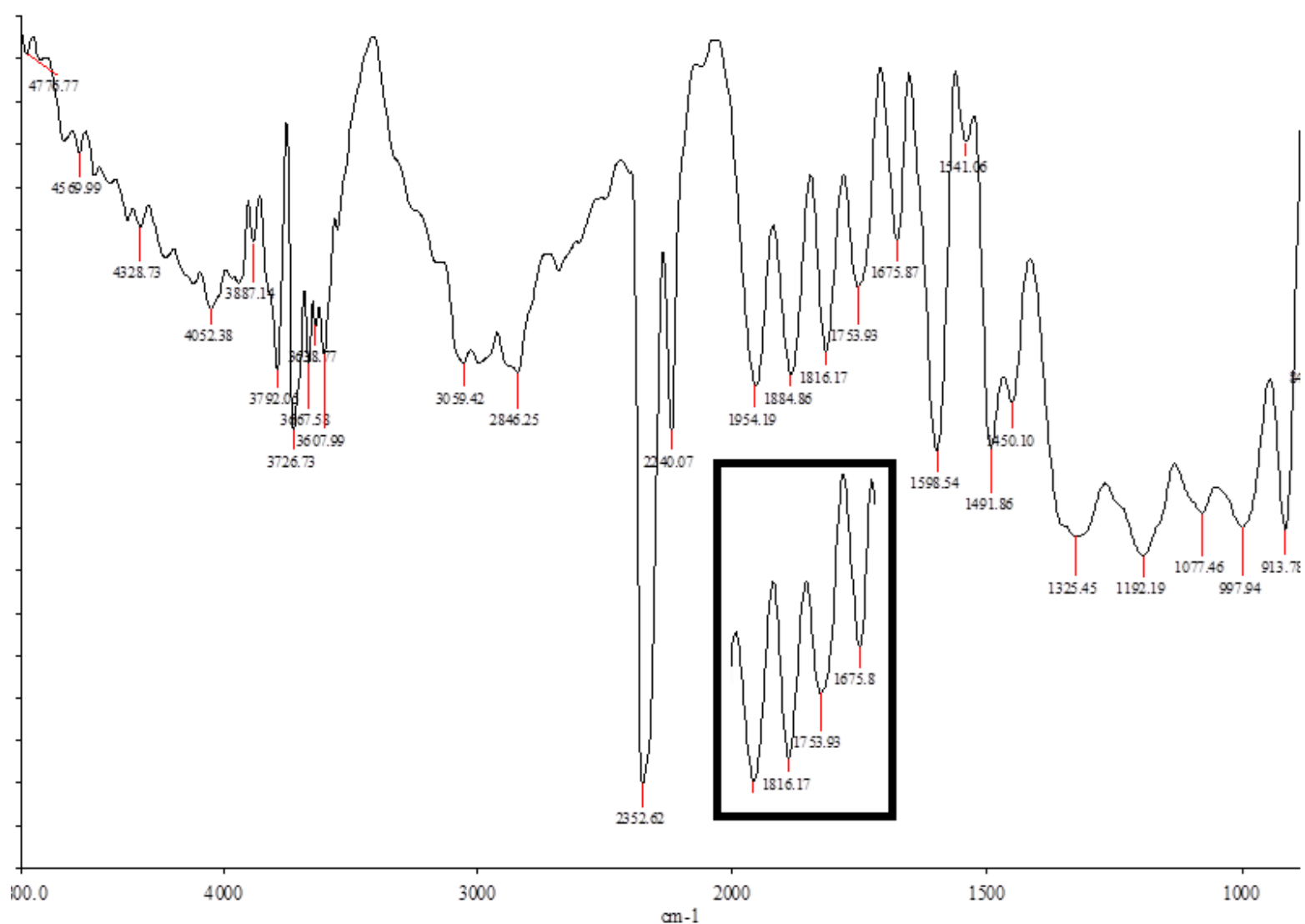

Fig. 12: FTIR of ABS/Casein/nano Si blends after 4-month degradation (15\% casein)

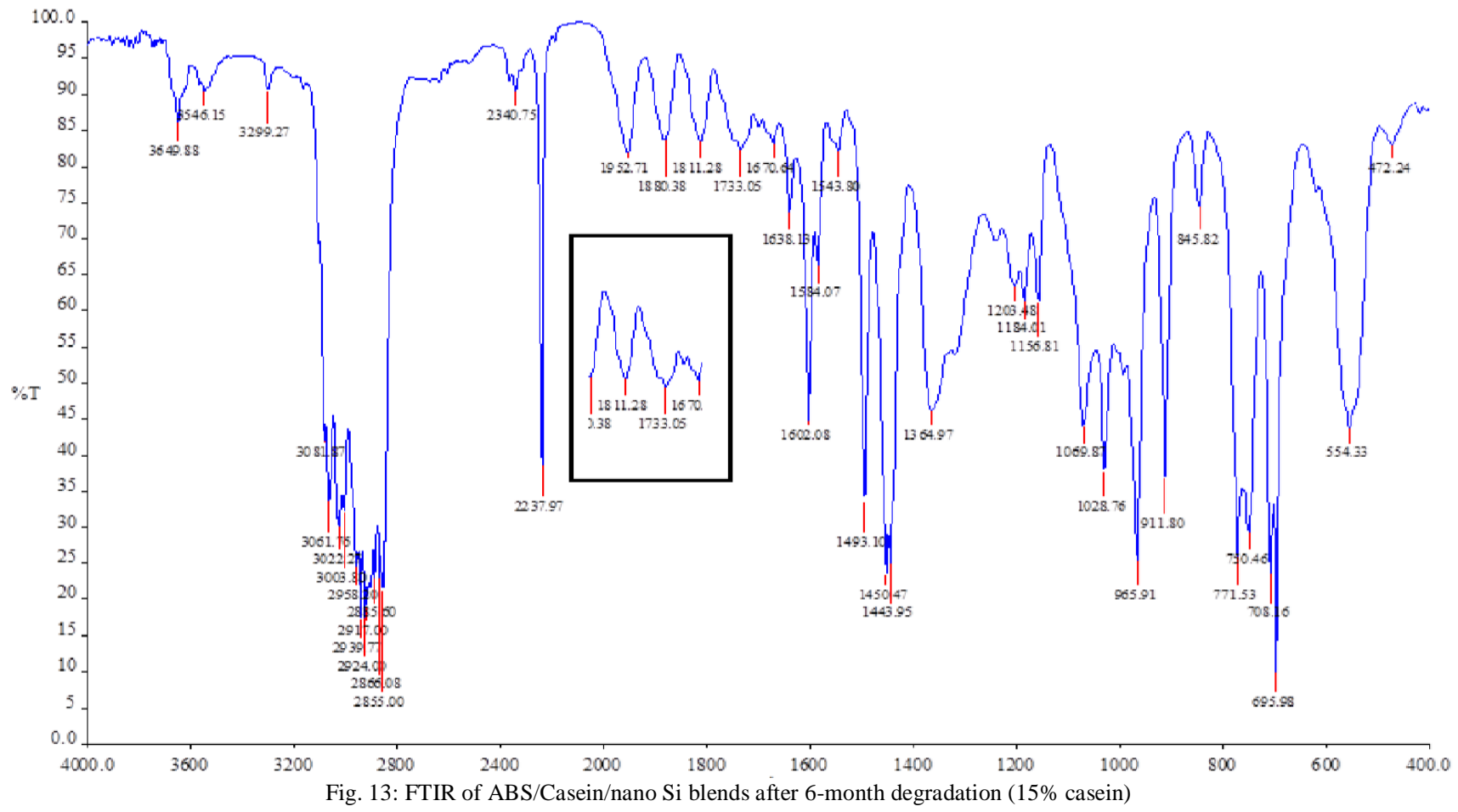

\section{Conclusions}

ABS/Casein/nano si nanocomposites usually are pseudo plastics in behavior, along with the shear sensitivity of the composites is more than that of pure ABS. Mechanical results show that the strain at break of the composites decreases sharply with increasing casein content, and the same behavior is noted in the stress at the break in casein levels higher than 15 w\%, whereas Young's modulus of the composites is higher than that of the pure polymer. To improve the impact properties of nanoparticles in general and ABS in this research nano silica was used, so that the results of the mechanical properties and 
the resistance to shock increased, however ABS/Casein/nano $\mathrm{Si}$ is a highly biodegradable nanocomposites and showed strengthened the mechanical and physical properties. With increasing protein (casein) biodegradation of $\mathrm{ABS} /$ nano $\mathrm{Si}$ nanocomposites can be much less time to adjust to environmental.by adding nano silica until $3 \mathrm{w} \%$ to the biodegradable ABS/casein the impact strength increases and with the rising of amount nano silica weight more than $3 \mathrm{w} \%$ the impact strength is diminished. This phenomenon can also be observed in tensile strength. The results showed that nanocomposites with $15 \mathrm{w} \%$ casein have appropriate mechanical properties, and good process capability. The addition of casein to ABS plastics has been promoted as a technique to attain biodegradability. Blends with casein indicate more degradability compared to pure ABS. The obtained results indicate that casein a natural crude material can be used as an environmentally-friendly alternative to other materials, and has superior properties.

\section{Acknowledgment}

Support of this work from Shiraz Branch, Islamic Azad University, Shiraz, Iran, and the Iran Nanotechnology Initiative Council is gratefully acknowledged.

\section{Ethical issue}

Authors are aware of, and comply with, best practice in publication ethics specifically with regard to authorship (avoidance of guest authorship), dual submission, manipulation of figures, competing interests and compliance with policies on research ethics. Authors adhere to publication requirements that submitted work is original and has not been published elsewhere in any language.

\section{Competing interests}

The authors declare that there is no conflict of interest that would prejudice the impartiality of this scientific work.

\section{Authors' contribution}

All authors of this study have a complete contribution for data collection, data analyses and manuscript writing.

\section{Reference}

1. Gregory MR. Environmental implications of plastic debris in marine settings - entanglement, ingestion, smothering, hangerson, hitch-hiking and alien invasions. Philosophical Transactions of the Royal Society B: Biological Sciences. 2009;364(1526):201325 .

2. Jayasekara R, Harding I, Bowater I, Lonergan G. Biodegradability of a selected range of polymers and polymer blends and standard methods for assessment of biodegradation. Journal of Polymers and the Environment. 2005;13(3):231-51.

3. Goudarzian N, Hashemi S, Mirjalili M. Unsaturated polyester resins modified with cresol novolac epoxy and silica nanoparticles: processing and mechanical properties. Int $\mathrm{J}$ Chem Pet Sci. 2016;5(1):13-26.

4. Davis G. Characterization and characteristics of degradable polymer sacks. Materials Characterization. 2003;51(2-3):147-57.

5. Tan Z, Xu X, Sun S, Zhou C, Ao Y, Zhang H, et al. Influence of rubber content in $\mathrm{ABS}$ in wide range on the mechanical properties and morphology of PC/ABS blends with different composition. Polymer Engineering \& Science. 2006;46(10):1476-84

6. Mousavi S, Esmaeili H, Arjmand O, Karimi S, Hashemi S. Biodegradation study of nanocomposites of phenol novolac epoxy/unsaturated polyester resin/egg shell nanoparticles using natural polymers. Journal of Materials. 2015;2015:1-6.

7. Mousavi S, Aghili A, Hashemi S, Goudarzian N, Bakhoda Z, Baseri S. Improved morphology and properties of nanocomposites, linear low density polyethylene, ethylene-co-vinyl acetate and nano clay particles by electron beam. Polymers from Renewable Resources. 2016;7(4):135-53.

8. Liang J-Z Melt extrusion properties of ABS and ABS-quasinano$\mathrm{CaCO} 3$ composite. Journal of Elastomers \& Plastics. 2004;36(4):363-74.

9. Debbah I, Krache R, Aranburu N, Etxeberria A, Pérez E Benavente R. Influence of ABS Type and Compatibilizer on the Thermal and Mechanical Properties of PC/ABS Blends. International Polymer Processing. 2020;35(1):83-94.

10. Massam J, Pinnavaia TJ. Clay nanolayer reinforcement of a glassy epoxy polymer. MRS Online Proceedings Library Archive. 1998;520.

11. Mousavi SM, Hashemi SA, Salahi S, Hosseini M, Amani AM, Babapoor A. Development of clay nanoparticles toward bio and medical applications. Current Topics in the Utilization of Clay in Industrial and Medical Applications. 2018;9:167.

12. Mousavi SM, Hashemi SA, Ghasemi Y, Amani AM, Babapoor A Arjmand O. Applications of graphene oxide in case of nanomedicines and nanocarriers for biomolecules: review study. Drug metabolism reviews. 2019;51(1):12-41.

13. Ray SS, Okamoto M. Polymer/layered silicate nanocomposites: a review from preparation to processing. Progress in polymer science. 2003;28(11):1539-641.

14. Tadmor Z, Gogos CG. Principles of polymer processing: John Wiley \& Sons; 2013

15. Bahrani S, Hashemi SA, Mousavi SM, Azhdari R. Zinc-based metal-organic frameworks as nontoxic and biodegradable platforms for biomedical applications: review study. Drug metabolism reviews. 2019;51(3):356-77.

16. Atapour A, Negahdaripour M, Ghasemi Y, Razmjuee D, Savardashtaki A, Mousavi SM, et al. In silico designing a candidate vaccine against breast cancer. International Journal of Peptide Research and Therapeutics. 2020;26(1):369-80.

17. Sarojini S, Avatar S, Subhendu B, Lokesh C. Effects of nanosilica/nano-alumina on mechanical and physical properties of polyurethane composites and coatings. Transact Electric Electron Mater. 2013;14:1-8.

18. Amani AM, Hashemi SA, Mousavi SM, Abrishamifar SM, Vojood A. Electric field induced alignment of carbon nanotubes: methodology and outcomes. Carbon nanotubes-recent progress: IntechOpen; 2017.

19. Quercia G, Lazaro A, Geus J, Brouwers H. Characterization of morphology and texture of several amorphous nano-silica particles used in concrete. Cement and Concrete Composites. 2013;44:7792.

20. Choi YS, Xu M, Chung IJ. Synthesis of exfoliated poly (styreneco-acrylonitrile) copolymer/silicate nanocomposite by emulsion polymerization; monomer composition effect on morphology. Polymer. 2003;44(22):6989-94.

21. Mousavi S, Zarei M, Hashemi S. Polydopamine for biomedical application and drug delivery system. Med Chem (Los Angeles). 2018;8:218-29.

22. Zheng Y, Zheng Y, Ning R. Effects of nanoparticles SiO2 on the performance of nanocomposites. Materials Letters. 2003;57(19):2940-4

23. Mousavi S, Arjmand O, Hashemi S, Banaei N. Modification of the epoxy resin mechanical and thermal properties with silicon acrylate and montmorillonite nanoparticles. Polymers from Renewable Resources. 2016;7(3):101-13.

24. Yousefi K, Manesh HD, Khalifeh A, Moazami F, Sanaee M. Nanocement/poly (vinyl alcohol) composites for endodontic applications. Materials Chemistry and Physics. 2020:123337.

25. Lorenzen PC, Schrader K. A comparative study of the gelation properties of whey protein concentrate and whey protein isolate. Le Lait. 2006;86(4):259-71.

26. Mousavi M, Hashemi A, Arjmand O, Amani AM, Babapoor A Fateh MA, et al. Erythrosine Adsorption from Aqueous Solution via Decorated Graphene Oxide with Magnetic Iron Oxide Nano Particles: Kinetic and Equilibrium Studies. Acta Chimica Slovenica. 2018;65(4):882-94

27. Keri Marshall N. Therapeutic applications of whey protein Alternative medicine review. 2004;9(2):136-56.

28. Hashemi SA, Mousavi SM, Ramakrishna S. Effective removal of mercury, arsenic and lead from aqueous media using Polyaniline- 
Fe3O4-silver diethyldithiocarbamate nanostructures. Journal of Cleaner Production. 2019;239:118023.
29. Standard B, ISO B. Plastics-Determination of tensile properties_. Part. 1996;1:527-1. 